\title{
PEMANFAATAN OLI BEKAS HIDROLIK YANG DICAMPUR DENGAN SOLAR TERHADAP EMISI GAS BUANG PADA MESIN DIESEL
}

\author{
Bagus Lutfiwijaya ${ }^{1)}$, Akhmad Syarief ${ }^{2)}$, Sigit Mujiarto ${ }^{3)}$ \\ 1)2)Program Studi Teknik Mesin, Fakultas Teknik, Universitas Lambung Mangkurat \\ ${ }^{3)}$ Jurusan Teknik Mesin, Politeknik Negeri Banjarmasin \\ Program Sarjana, Universitas Lambung Mangkurat \\ JL. Akhmad Yani Km. 36 Banjarbaru, Kalimantan selatan, 70714 \\ Telp. 0511- 4772646, Fax 0511-4772646 \\ Email : lutfiwijaya999@rocketmail.com
}

\begin{abstract}
Used hydraulic oil SAE 10 is a waste activities that are often found in Indonesia, especially in mining and plantantion scale hydraulic large. Waste used oil SAE 10 can be used as a fuel mixture of hydrocarbons is done by mixing the used oil hydraulic SAE 10 with other fuels such as gasoline, kerosene, diesel fuel with the addition of a maximum percentage of less than 50\%. this research tries to investigate exhaust emissions on diesel engines with hydraulic mixing used oil into diesel fuel with a mixture of different variations. The machine used is a four-stroke diesel engine with a maximum power of $4.4 \mathrm{~kW}$. Be based testing has been done variations of a mixture of $5 \%$ and $10 \%$ is still within the allowed limits.
\end{abstract}

Keywords: Diesel engine, Used hydraulic oil, Exhaust emissions.

\section{PENDAHULUAN}

Minyak hidrolik (Oli hidrolik) atau Hidrolic oil adalah bagian terpenting dalam sistem hidrolik yang mana berfungsi sebagai penerus gaya, sebagai pelumas komponen hidrolik, dan pendingin. setelah pemakaian selama beberapa waktu peformanya menjadi berkurang karena tekanan dan panas sehingga disebut minyak hidrolik bekas

Oli hidrolik bekas bersifat pencemar dan termasuk dari Bahan Berbahaya dan Beracun (B3) karena itu memerlukan penanganan yang tepat dan praktis. Bila dilihat dari komposisi kimianya oli hidrolik terbuat minyak bumi dan ada juga yang terbuat dari minyak sintesis (minyak yang berasal dari proses kimia) maupun campuran minyak bumi dan minyak sintesis yang ditambah berbagai bahan kimia aditif guna meningkatkan kualitas dari oli hidrolik.

Di pulau kalimantan yang terkenal dengan perusahaan perkebunan (sawit,karet,dll) dan Pertambangannya memerlukan alat berat untuk mengangkut hasil perkebunan dan tambang, seperti HD dumptruck, Pc expator,dll. Dan alat tersebut memerlukan perawatan, seperti penggantian oli mesin, oli hirolik, dsb. Pada Km tertentu atau jam. Berlimpahnya oli hidrolik bekas dan hanya disimpan dipenampungan dan tidak tau mau diapakan lagi.

Menurut Hudoyono roy limbah oli bekas dapat dimanfaatkan sebagai bahan bakar campuran hidrokarbon dilakukan dengan mencampurkan oli bekas dengan bahan bakar lainya seperti bensin, minyak tanah, solar dengan presentase penambahan maksimal kurang dari $50 \% .^{(1)}$

Batasan masalah dari pengujian emisi gas buang adalah bahan bakar yang digunakan dalam pengujian adalah solar dengan variasi campuran oli bekas hidrolik sebanyak 5\%,10\%,15\%,20\%. 
Tujuan yang ingin di capai dalam penelitian adalah untuk mengetahui emisi gas buang mesin diesel bahan bakar solar dengan variasi campuran yang berbeda apakah masih dalam ambang batas yang diizinkan.

\section{TINJAUAN PUSTAKA}

Emisi gas buang merupakan polutan (bahan atau benda yang menyebabkan pencemaran) yang mencemari udara yang dihasilkan oleh gas buang kendaraan. Gas buang kendaraan yang dimaksud disini adalah gas sisa proses pembakaran yang dibuang ke udara bebas melalui saluran buang kendaraan.

\subsection{Asal Mula Polutan}

Dalam pembakaran bahan bakar dengan oksigen dari udara yang mengandung $21 \%$, volume $\mathrm{O} 2<1 \%$ dari gas yang terkandung, dan nitrogen, realisasi energi panas pada reaksi eksotermik. Pelepasan panas oleh bahan bakar berdasarkan hidrokarbon seperti bensin dan solar ditentukan oleh banyaknya reaksi yang tidak sempurna dikarenakan komposisi hidrogen dalam bahan bakar. Komponen bahan bakar yang terpenting adalah parafin,olefin, dan aromates.

Pembakaran sempurna dari hidrokarbon dalam kondisi ideal atau ketika ada kelebihan udara, secara teoritis hanya karbon dioksida dan air muncul serta nitrogen dari udara, dan bawaan dari oksigen. Selain komponen utama dari gas buang seperti karbon dioksida $\left(\mathrm{CO}_{2}\right)$ dan uap air adalah utama perwakilan dari pencemar), karbon monoksida, dan hidrokarbon yang tidak terbakar, dan nitrogen oksida (NOx). Bahan Pencemar utamanya timbul dari gangguan rantai reaksi disebabkan oleh pembakaran dengan waktu singkat di dalam ruang bakar, maka kesetimbangan tidak ada lagi. Inhomogeneities dalam campuran dari berbagai rasio udara-bahan bakar $(\lambda)$, efek pembakaran pada dinding ruang, dan kotoran dan zat aditif dalam bahan bakar juga berkontribusi terhadap yang tak diinginkan dari emisi yang dihasilkan, seperti pada gambar Gambar

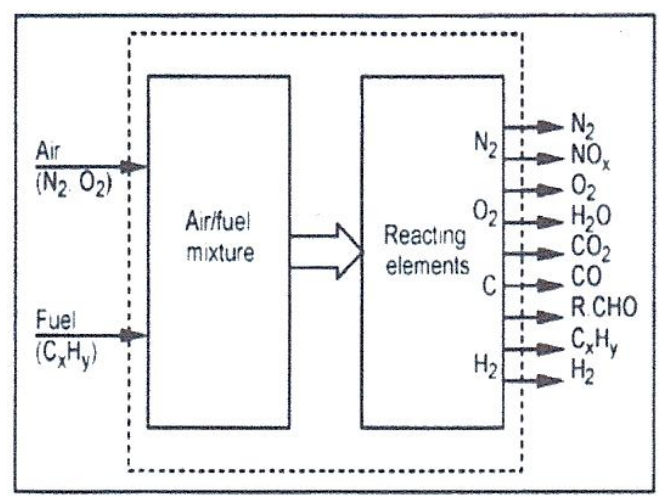

Gambar 1. Mekanisme Reaksi Di Ruang Pembakaran

(Sumber: Van, Schafer, 2004)

\subsection{Bentuk-bentuk Emisi Gas Buang}

Semua zat yang terkandung pada gas buang akan menjadi sangat berbahaya ketika "dikonsumsi" dengan jumlah yang berlebihan. Secara umum, terdapat 2 sumber pencemaran 
udara, yaitu pencemaran akibat sumber alamiah (natural sources), seperti letusan gunung berapi, dan yang berasal dari kegiatan manusia (anthropogenic sources), seperti yang berasal dari transportasi, emisi pabrik, dan lain-lain.

Peraturan pemerintah berdasarkan Undang-Undang Nomor 23 tahun 1997 pasal 1 ayat 12 mengenai Pencemaran Lingkungan yaitu pencemaran yang disebabkan oleh aktivitas manusia seperti pencemaran yang berasal dari pabrik, kendaraan bermotor, pembakaran sampah, sisa pertanian, dan peristiwa alam seperti kebakaran hutan, letusan gunung api yang mengeluarkan debu, gas, dan awan panas.

Selain itu, pencemaran udara dapat pula diartikan adanya bahan-bahan atau zat asing di dalam udara yang menyebabkan terjadinya perubahan komposisi udara dari susunan atau keadaan normalnya. Kehadiran bahan atau zat asing tersebut di dalam udara dalam jumlah dan jangka waktu tertentu akan dapat menimbulkan gangguan pada kehidupan manusia, hewan, maupun tumbuhan.

Jenis-Jenis Pencemaran Udara

Ada beberapa jenis pencemaran udara, yaitu :

a. Gas, adalah uap yang dihasilkan dari zat padat atau zat cair karena dipanaskan atau menguap sendiri. Contohnya : gas hasil pembakaran

b. Partikel, adalah suatu bentuk pencemaran udara yang berasal dari zarah-zarah kecil yang terdispersi ke udara, baik berupa padatan, cairan, maupun padatan dan cairan secara bersama-sama. Contohnya: debu, asap,dan lain-lain.

\subsection{Bentuk-bentuk Emisi Gas Buang sebagai berikut :}

\section{a. Hydrokarbon (HC)}

Zat ini kadang-kadang disebut sebagai senyawa organik yang mudah menguap. Hidrokarbon merupakan uap bensin yang tidak terbakar dan produk samping dari pembakaran tak sempurna.

\section{b. Karbonmonoksida(CO)}

Gas karbon monoksida (CO) adalah gas yang dihasilkan dari proses oksidasi bahan bakar yang tidak sempurna. Gas ini bersifat tidak berwarna, tidak berbau, tidak menyebabkan iritasi, tidak berasa. CO diproduksi dari pembakaran bakan bakar fosil yang tidak sempurna, seperti bensin, solar dan kayu bakar.

Gas karbon monoksida ( $\mathrm{CO}$ ) adalah gas yang relatif tidak stabil dan cenderung bereaksi dengan unsur lain. Gas karbon monoksida (CO) merupakan gas yang sangat sangat sulit dideteksi karena gas $\mathrm{CO}$ tidak memiliki bau, rasa dan bentuk.

\section{c. Karbon dioksida $\left(\mathrm{CO}_{2}\right)$}

Karbon dioksida $\left(\mathrm{CO}_{2}\right)$ adalah gas yang diemisikan dari sumber-sumber alamiah dan antropogenik. Karbon dioksida adalah gas yang secara alamiah berada di atmosfer Bumi, berasal dari emisi gunung berapi dan aktivitas mikroba di tanah dan lautan. Tetapi akibat aktivitas manusia (pembakaran batubara, minyak dan gas alam, pembakaran dalam kendaraan 
bermotor dan mesin pabrik) konsentrasi global $\mathrm{CO}_{2}$ semakin meningkat. Masalah utama dari peningkatan $\mathrm{CO}_{2}$ adalah perubahan iklim. Karbon dioksida juga dapat menyebabkan hujan asam karena akan larut di dalam air hujan dan membentuk asam karbonat, menyebabkan air hujan bersifat lebih asam bila dibandingkan dengan air tawar. Hujan asam dapat menyebabkan kerusakan hutan, kematian biota laut dan kerusakan bangunan.

\section{d. Nitrogen oksida (NOx)}

Senyawa NOx adalah ikatan kimia antara unsur nitrogen dan oksigen. Nitrogen adalah gas yang amat stabil yang tidak akan berikatan dengan unsur lain. Tetapi dalam kondisi suhu tinggi dan tekanan tinggi dalam ruang bakar, nitrogen akan memecah ikatannya dan berikatan dengan oksigen.

Senyawa NOx ini sangat tidak stabil dan bila terlepas ke udara bebas, akan berikatan dengan oksigen untuk membentuk $\mathrm{NO}_{2}$. Inilah yang amat berbahaya karena senyawa ini amat beracun dan bila terkena air akan membentuk asam nitrat.

\section{e. Sulfur dioksida $\left(\mathrm{SO}_{2}\right)$}

Gas sulfur dioksida $\left(\mathrm{SO}_{2}\right)$ adalah gas yang tidak berbau bila berada pada konsentrasi rendah tetapi akan memberikan bau yang tajam pada konsentrasi pekat. Sulfur dioksida berasal dari pembakaran bahan bakar fosil,( seperti minyak bumi dan batubara) dan peleburan logam.

\subsection{Baku Mutu Mesin Diesel}

Tabel 1. Baku Mutu Mesin Diesel

\begin{tabular}{|c|l|c|c|}
\hline No & \multicolumn{1}{|c|}{ Zat } & Baku Mutu & Satuan \\
\hline 1 & Hydrokarbon $(\mathrm{HC})$ & 200 & $\mathrm{Ppm}$ \\
\hline 2 & Karbon monoksida (CO) & 1.5 & $\%$ \\
\hline 3 & Karbon dioksida $\left(\mathrm{CO}_{2}\right)$ & 1.5 & $\%$ \\
\hline 4 & Nitrogen oksida $\left(\mathrm{NO}_{x}\right)$ & 70 & $\mathrm{Ppm}$ \\
\hline 5 & Sulfur dioksida $\left(\mathrm{SO}_{2}\right)$ & 70 & $\mathrm{Ppm}$ \\
\hline 6 & Opacity & 70 & $\%$ \\
\hline
\end{tabular}

Sumber, Dinas Perhibungan Banjarbaru

\section{METODOLOGI PENELITIAN}

Bahan yang menjadi objek pengujian ini adalah solar dan solar dengan campuran oli bekas dengan presentase campuran 5\%,10\%,15\%,dan 20\%. Menggunakan mesin diesel empat langkah, $2600 \mathrm{rpm}$ dengan daya output $4.4 \mathrm{~kW}$. Langkah-langkah penelitian dapat dilihat dalam diagram alir sebagai berikut: 


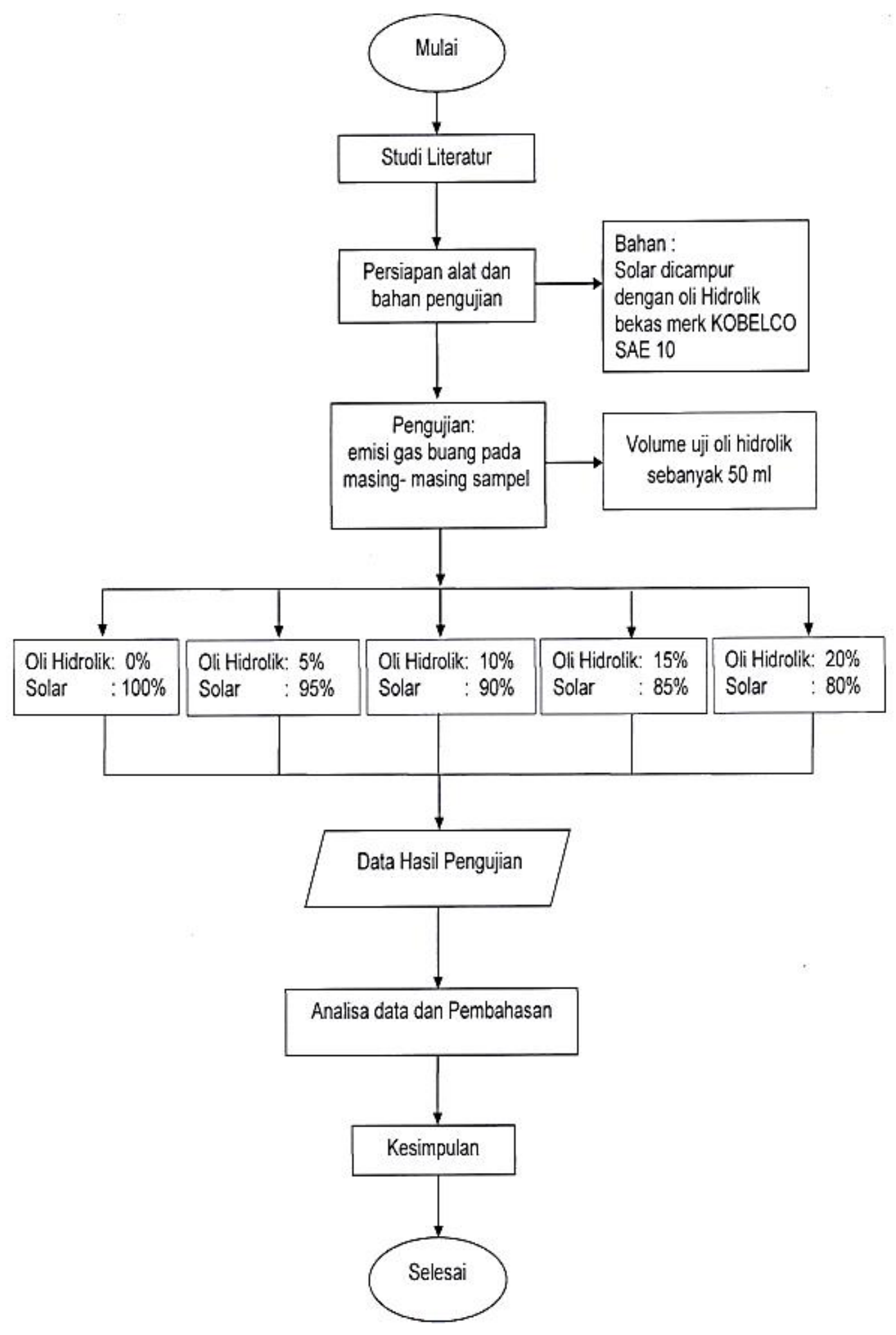

Gambar 2. Diagram Alir Metode Penelitian 


\section{HASIL DAN PEMBAHASAN}

\subsection{Hasil pengujian Hydrokarbon (HC)}

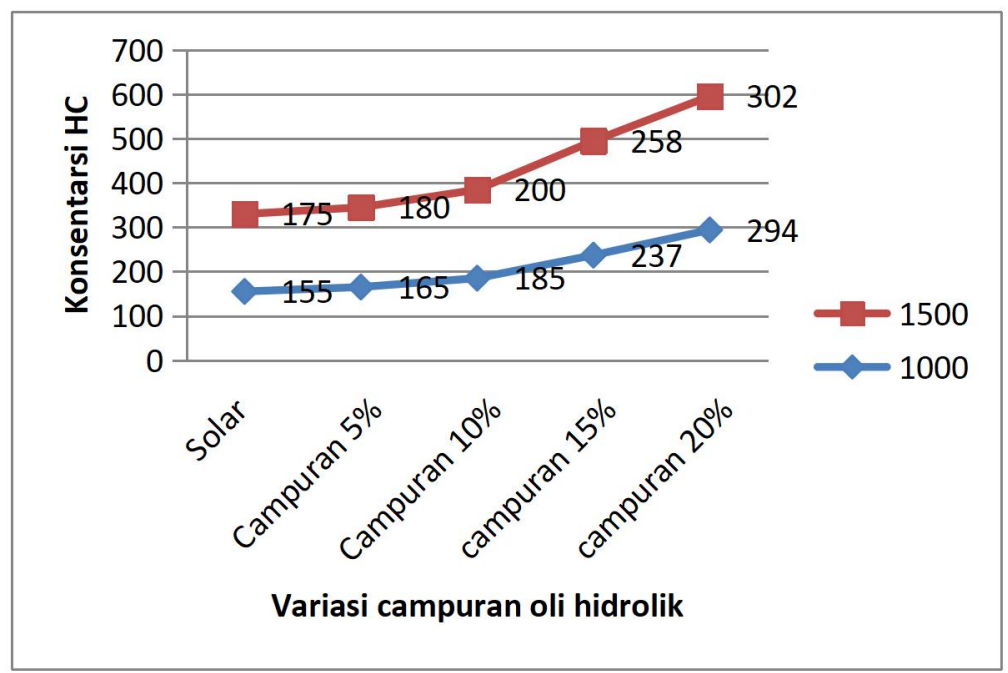

Gambar 3. Grafik Hasil Pengujian Hydrokarbon (HC)

Diketahui hasil dari zat hydrokarbon (HC) pada Rpm 1000, Solar, 155 Ppm, campuran $5 \%$, 165 Ppm, campuran 10 \%, 185 Ppm, dan 1500 Rpm, solar, 175 Ppm, campuran 5\%, 180 Ppm, Campuran 10 \%, 200 Ppm masih dalam ambang batas yang diizinkan. Dan pada Rpm 1000, campuran 15\%, 237 Ppm, campuran 20 \%, 294 Ppm dan 1500 Rpm, campuran 15 \%, 258 ppm, campuran $20 \%, 302 \mathrm{Ppm}$ melebihi ambang batas yang diizinkan.

\subsection{Hasil Pengujian Karbon Monoksida (CO)}

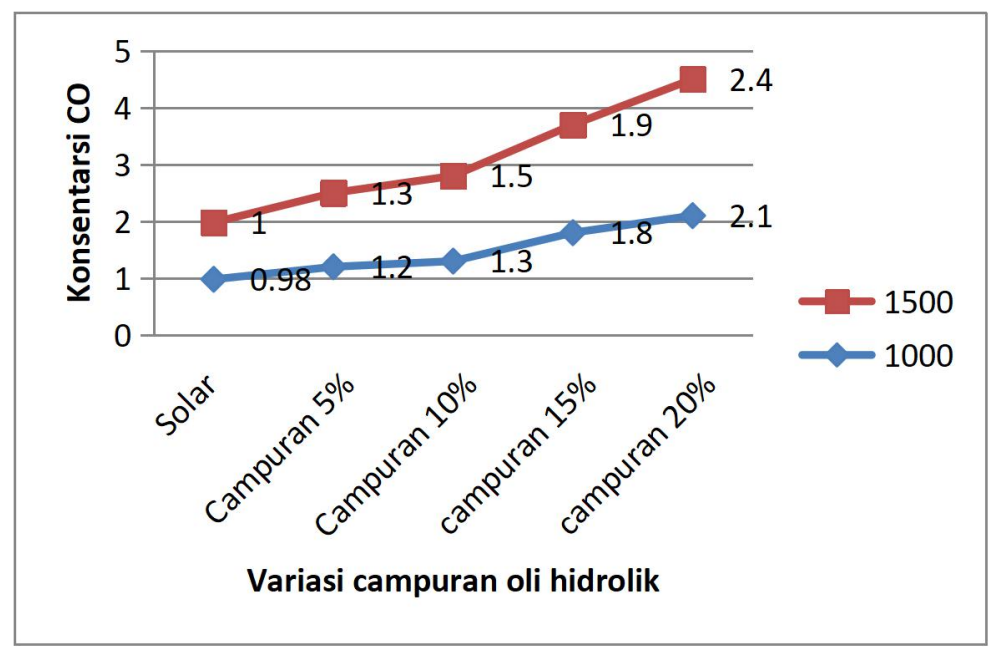

Gambar 4. Hasil Pengujian Karbon Monoksoda (CO) 
Diketahui hasil dari zat Karbon monoksida (CO) pada Rpm 1000, Solar, 0.98\%vol, campuran 5\%, 1.2\%vol, campuran $10 \%$, 1.3\%vol, dan 1500 Rpm, solar, 1\%vol, campuran 5\%, $1.3 \%$ vol, Campuran 10\%, $1.5 \%$ vol masih dalam ambang batas yang diizinkan. Dan pada Rpm 1000, campuran 15\%, 1.8\%vol, campuran 20\%, 2.1\%vol dan $1500 \mathrm{Rpm}$, campuran 15\%, $1.9 \%$ vol, campuran 20\%,2.4\%vol melebihi ambang batas yang diizinkan.

\subsection{Hasil Pengujian karbon dioksida $\left(\mathrm{CO}_{2}\right)$}

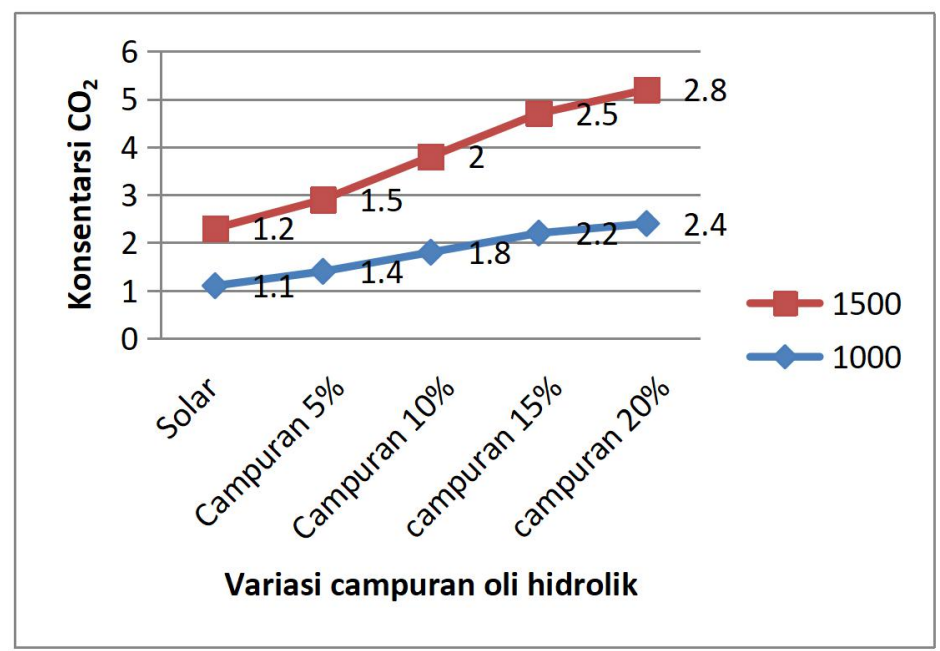

Gambar 5. Hasil Pengujian Karbon Dioksida $\left(\mathrm{CO}_{2}\right)$

Diketahui hasil dari zat Karbon monoksida (CO) pada Rpm 1000, Solar, 1.1\%vol, campuran 5\%, 1.4\%vol, dan 1500 Rpm, solar, 1.2\%vol, campuran 5\%, 1.5\%vol, masih dalam ambang batas yang diizinkan. Pada Rpm 1000 campuran 10\%, 1.8\%vol, dan Rpm 1500 Campuran 10\%, 2\%vol . Dan pada Rpm 1000, campuran 15\%, 2.2\%vol, campuran 20\%, 2.4\%vol dan 1500 Rpm, campuran $15 \%, 2.5 \%$ vol, campuran 20\%, 2.8\%vol melebihi ambang batas yang diizinkan. 


\subsection{Hasil Pengujian Nitrogen Dioksida $\left(\mathrm{NO}_{2}\right)$}

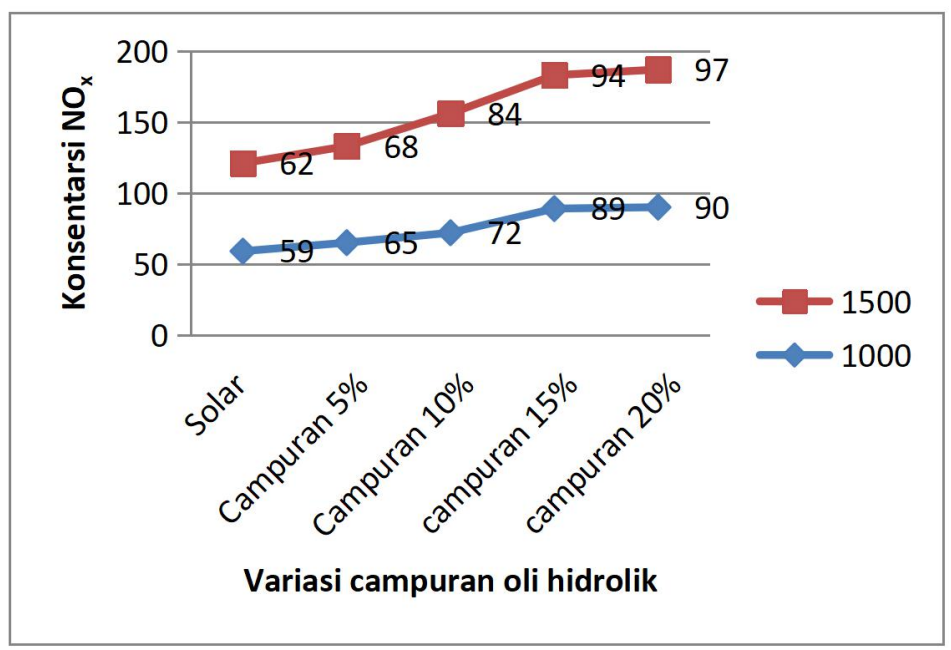

Gambar 6. Hasil Pengujian Nitrogen Dioksida $\left(\mathrm{NO}_{2}\right)$

Diketahui hasil dari zat Nitrogen Dioksida $\left(\mathrm{NO}_{2}\right)$ pada Rpm 1000, Solar, 59 Ppm, campuran 5\%, 65 Ppm masih dalam ambang batas yang diizinkan. Pada Rpm 1000 campuran 10\%, 72 Ppm, dan 1500 Rpm, solar, 62 Ppm, campuran 5\%, 68 Ppm, dan pada Rpm 1000 Campuran 10\%, 84 Ppm, campuran 15\%, 89 Ppm, campuran 20\%, 90 Ppm dan $1500 \mathrm{Rpm}$, campuran 15\%, 94 ppm, campuran 20\%, 97 Ppm melebihi ambang batas yang diizinkan.

\subsection{Hasil Pengujian Sulfur Dioksida $\left(\mathrm{SO}_{2}\right)$}

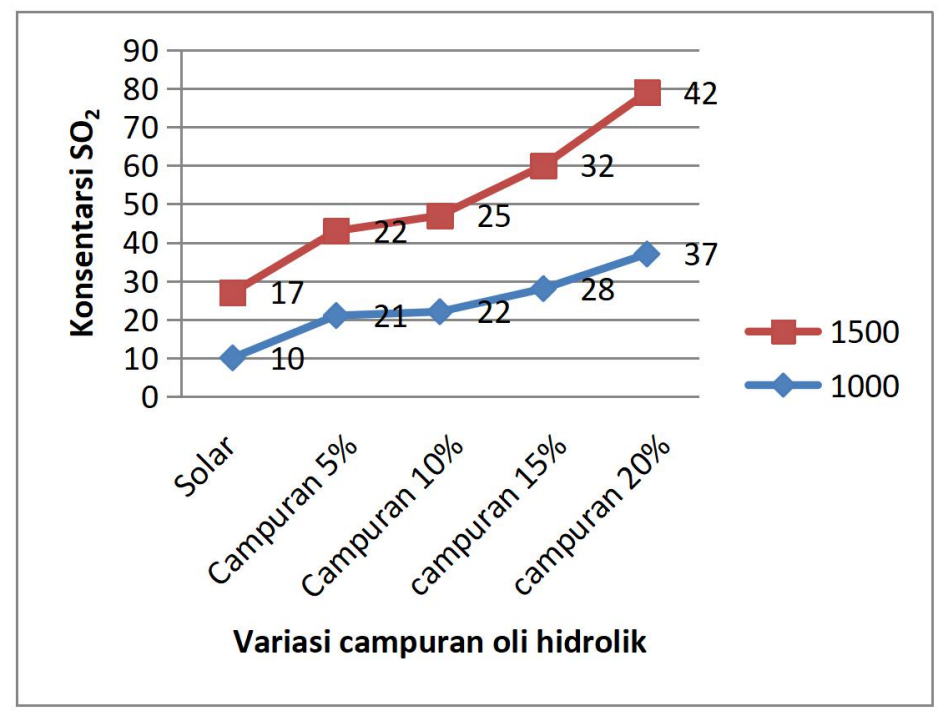

Gambar 7. Hasil Pengujian Sulfur Dioksida $\left(\mathrm{SO}_{2}\right)$ 
diatas diketahui hasil dari zat Sulfur dioksida $\left(\mathrm{SO}_{2}\right)$ pada Rpm 1000, Solar, $10 \mathrm{Ppm}$, campuran 5\%, $21 \mathrm{Ppm}$, campuran 10\%, 22 Ppm, campuran 15\%, 28 Ppm, campuran 20\%, 37 Ppm dan 1500 Rpm, solar, 17 Ppm, campuran 5\%, 22 Ppm, Campuran 10\%, 25 Ppm, campuran 15\%, 32 ppm, campuran 20\%, 42 Ppm masih dalam ambang batas yang diizinkan.

\subsection{Hasil Pengujian Opasitas (Kepekatan Asap)}

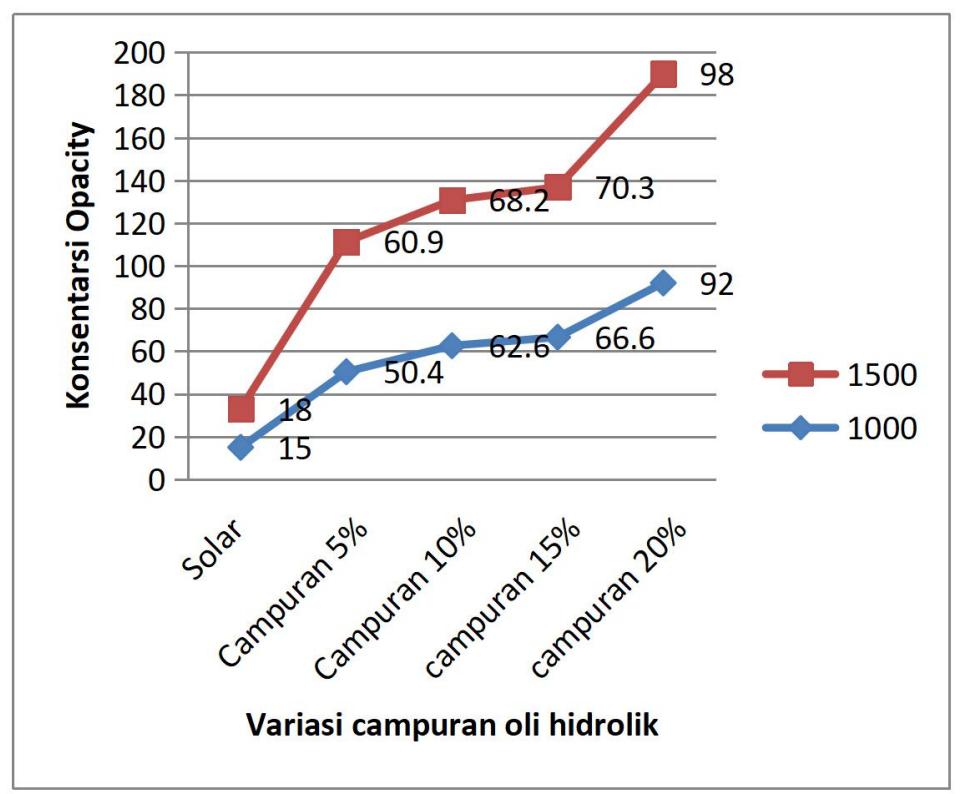

Gambar 8. Hasil Pengujian Opasitas (Kepekatan Asam)

Diketahui hasil dari pengujian Opasitas (kepekatan asap) pada Rpm 1000, Solar, 15\%, campuran 5\%, 50.4\%, campuran 10\%, 66.6\%, dan 1500 Rpm, solar, 18\%, campuran 5\%, 60.9\%, masih dalam ambang batas yang diizinkan. Dan pada Rpm 1000, campuran 15\%, 66.6\%, campuran 20\%, 92\%, dan $1500 \mathrm{Rpm}$, Campuran 10\%, 70.3\%, campuran 15\%, 70.3\%, campuran 20\%, 98\%, melebihi ambang batas yang diizinkan.

\section{KESIMPULAN}

Dari hasil penelitian di dapatkan bahwa emisi gas buang bahan bakar solar dibandingkan dengan solar dengan campuran oli bekas hidrolik SAE 10 masih lebih baik solar tanpa campuran. Tapi pada campuran solar dengan oli bekas hidrolik SAE 10 5\%, 10\% emisi gas buang masih dalam batas emisi yang diizinkan. Dan solar dengan oli bekas hidrolik SAE 10 15\%, 20\% emisi gas buang melebihi batas emisi yang diizinkan. Jadi oli bekas hidrolik SAE 10 bisa dicampur dengan solar sebagai bahan campuran namun jumlahnya tidak melebihi $10 \%$. 


\section{REFERENSI}

[1] Havendri, Adly. 2008. Kaji Eksperimental Prestasi Dan Emisi Gas Buang Motor Bakar Diesel Menggunakan Variasi Campuran Bahan Bakar Biodiesel Minyak Jarak (Jatropha Curcas L) Dengan Solar. Skripsi, Fakultas Teknik: Universitas Andalas

[2] Hudoyo ,Roy. 2009. Pengujian Pengaruh Penambahan Material Pengotor Oli Bekas Jenuh Sebagai Identifikasi Kandungan Energy Pada Oli Murni. Universitas Kristen Satya Wacana.

[3] Nughroho, Putra, Bayu. 2014. Pengaruh Bahan Bakar Solar Dicampur Oli Bekas Terhadap Unjuk Kerja Mesin. Skripsi, Fakultas Teknik: Universitas Lambung Mangkurat

[4] Pulkrabek W. Willard. Engineering Fundamentals Of The Internal Combustion Engine. New Jersey. University Of Wisconsin. 